\title{
Patients with non-idiopathic sudden sensorineural hearing loss show hearing improvement more often than patients with idiopathic sudden sensorineural hearing loss
}

\author{
Jovanna Thielker ${ }^{1}$ (D) Anne Heuschkel ${ }^{2} \cdot$ Daniel Boeger $^{3} \cdot$ Jens Buentzel ${ }^{4} \cdot$ Dirk Esser $^{2} \cdot$ Kerstin Hoffmann $^{5}$. \\ Peter Jecker ${ }^{6} \cdot$ Andreas Mueller $^{7} \cdot$ Gerald Radtke $^{8} \cdot$ Orlando Guntinas-Lichius $^{1}$
}

Received: 22 October 2020 / Accepted: 8 February 2021 / Published online: 8 March 2021

(c) The Author(s) 2021

\begin{abstract}
Introduction To compare inpatient treated patients with idiopathic (ISSNHL) and non-idiopathic sudden sensorineural hearing loss (NISSNHL) regarding frequency, hearing loss, treatment and outcome.

Methods All 574 inpatient patients (51\% male, median age: 60 years) with ISSNHL and NISSNHL, who were treated in federal state Thuringia in 2011 and 2012, were included retrospectively. Univariate and multivariate statistical analyses were performed.

Results ISSNHL was diagnosed in 490 patients (85\%), NISSNHL in 84 patients (15\%). 49\% of these cases had hearing loss due to acute otitis media, 37\% through varicella-zoster infection or Lyme disease, $10 \%$ through Menière disease and $7 \%$ due to other reasons. Patients with ISSNHL and NISSNHL showed no difference between age, gender, side of hearing loss, presence of tinnitus or vertigo and their comorbidities. $45 \%$ of patients with ISSNHL and $62 \%$ with NISSNHL had an outpatient treatment prior to inpatient treatment $(p<0.001)$. The mean interval between onset of hearing loss to inpatient treatment was shorter in ISSNHL ( 7.7 days) than in NISSNHL (8.9 days; $p=0.02$ ). The initial hearing loss of the three most affected frequencies in pure-tone average (3PTAmax) scaled 72.9 dBHL $\pm 31.3 \mathrm{dBHL}$ in ISSNHL and 67.4 $\mathrm{dBHL} \pm 30.5 \mathrm{dBHL}$ in NISSNHL. In the case of acute otitis media, 3PTAmax (59.7 dBHL $\pm 24.6 \mathrm{dBHL})$ was lower than in the case of varicella-zoster infection or Lyme disease $(80.11 \mathrm{dBHL} \pm 34.19 \mathrm{dBHL} ; p=0.015)$. Mean absolute hearing gain $\left(\triangle 3\right.$ PTAmax $\left._{\mathrm{abs}}\right)$ was $8.1 \mathrm{~dB} \pm 18.8 \mathrm{~dB}$ in patients with ISSNHL, and not different in NISSNHL patients with $10.2 \mathrm{~dB} \pm 17.6 \mathrm{~dB}$. A $\triangle 3$ PTAmax $_{\mathrm{abs}} \geq 10 \mathrm{~dB}$ was reached in $34.3 \%$ of the patients with ISSNHL and to a significantly higher rate of $48.8 \%$ in NISSNHL patients $(p=0.011)$.
\end{abstract}

Conclusions ISSNHL and NISSNHL show no relevant baseline differences. ISSNHL tends to have a higher initial hearing loss. NISSHNL shows a better outcome than ISSNHL.

Keywords Idiopathic hearing loss $\cdot$ Non-idiopathic hearing loss $\cdot$ Acute otitis media $\cdot$ Zoster oticus

Orlando Guntinas-Lichius

jovanna.thielker@med.uni-jena.de

1 Department of Otorhinolaryngology, Jena University Hospital, Am Klinikum 1, 07747 Jena, Germany

2 Department of Otorhinolaryngology, HELIOS-Klinikum, Erfurt, Germany

3 Department of Otorhinolaryngology, Zentralklinikum, Suhl, Germany

4 Department of Otorhinolaryngology, Südharz-Krankenhaus gGmbH, Nordhausen, Germany
5 Department of Otorhinolaryngology, Sophien/Hufeland-Klinikum, Weimar, Germany

6 Department of Otorhinolaryngology, Klinikum Bad Salzungen, Bad Salzungen, Germany

7 Department of Otorhinolaryngology, SRH Wald-Klinikum, Gera, Germany

8 Department of Otorhinolaryngology, Ilm-Kreis-Kliniken, Arnstadt, Germany 


\section{Introduction}

So far, many studies have analyzed epidemiological data for idiopathic sudden sensorineural hearing loss (ISSNHL) $[1,2]$. In a previous study on the ISSNHL, left side, nondeclining audiogram type and no previous outpatient treatment as independent prognostic factors for a better recovery could be found [3]. Profound hearing loss, hearing loss in older patients, delayed treatment and arterial hypertension were negative prognostic factors in another study [4]. In sum, there are high reported recovery rates up to $32 \%$ to $65 \%[5,6]$. There are some uncertainties due to therapy strategies but the possible therapy strategies are discussed extensively in therapy recommendations [7]. Systemic glucocorticoid, rheological therapy, local glucocorticoid therapy or even a wait-and-see strategy is currently recommended [8].

In contrast, not much is known on the outcome of nonidiopathic sudden sensorineural hearing loss (NISSNHL), because in all studies analyzing hearing loss and recovery these patients are excluded $[9,10]$. The aim of this work is therefore to define whether an underlying cause of hearing loss in patients with NISSNHL is associated with a different prognosis for hearing gain than is the case with ISSNHL.

In the federal state of Thuringia, there are eight hospitals with departments for ears-nose-throat (ENT) medicine. These have formed a network for the scientific evaluation of ENT diseases [11, 12]. Recently, we have published data on all patients who were hospitalized in Thuringia in 2011 and 2012 for treatment of ISSNHL [3, $11,12]$. Here, we compare now the results of these patients with ISSNHL to the patients treated for NISSNHL in the same time period.

\section{Methods}

\section{Study design and patients}

We performed a retrospective analysis in all eight ENT departments of the federal state Thuringia. All patients who were hospitalized in 2011 and 2012 due to acute hearing loss with the ICD codes (International Classification of Diseases) H91.0, H91.1, H91.2, H91.3, H91.8 and H91.9 were included in the study. A positive ethical vote for the evaluation of the underlying data was obtained (No. 2726-12/09, 4755-0416). A total of 723 patients with the above-mentioned diagnoses were treated as inpatient patients and were included in the primary dataset. It made no difference whether the patients had comorbidities or had already received prior outpatient treatment. 58 patients were initially excluded from the evaluation due to missing data sets (e.g. no initial hearing investigation) and 91 patients were excluded due to a lack of initial hearing loss, inpatient treatment due to middle ear surgery or cochlear implantation or lack of follow-up hearing examinations. Of the remaining 574 patients, 490 had an idiopathic sudden sensorineural hearing loss (ISSNHL) while the remaining 84 patients had a disease underlying the hearing loss (Menière disease, acute otitis media, Lyme disease, varicella-zoster infection) and were classified as NISSNHL. All 574 patients, ISSNHL as well as NISSNHL, were examined in the present study (Supplemental Digital Content 1).

The follow-up was recorded and evaluated until August 2013. Patient data such as age and gender, clinical and functional examination, medical and surgical treatment were recorded and the treatment of hearing loss in the case of ISSNHL compared to NISSNHL was evaluated.

The extent of the initial hearing loss was described using the pure-tone average (PTA) in decibels hearing level ( $\mathrm{dB}$ $\mathrm{HL})$. The average hearing loss of the three most affected frequencies (3PTAmax), 10 frequencies (10PTA: 0.125; $0.25 ; 0.5 ; 1 ; 1.5 ; 2 ; 3 ; 4 ; 6 ; 8 \mathrm{kHz}), 9$ frequencies (9PTA: $0.125 ; 0.25 ; 0.5 ; 1 ; 2 ; 3 ; 4 ; 6 ; 8 \mathrm{kHz})$, 4frequencies (4PTA: $0.5 ; 1 ; 2 ; 4 \mathrm{kHz})$, low- (LF3PTA: $0.125 ; 0.5 ; 1 \mathrm{kHz}$ ), middle- (MF3PTA: 2; 3; $4 \mathrm{kHz}$ ), and high frequency (HF2PTA: $6 ; 8 \mathrm{kHz}$ ) hearing loss were calculated $[3,13,14]$. Hearing losses that were not technically measurable and deafness were considered as hearing loss of $120 \mathrm{~dB}$. According to Plontke et al., the outcome was calculated as an absolute hearing improvement before therapy compared to the followup $\left(\Delta \mathrm{PTA}_{\mathrm{abs}}=\mathrm{PTA}_{\text {pre }}\right.$ minus PTA $\left.\mathrm{Post}_{\text {in }} \mathrm{dB}\right)$ [13]. Furthermore, relative (rel) hearing improvement was calculated as $\Delta \mathrm{PTA}_{\text {rel }}=100 *\left(\mathrm{PTA}_{\text {pre }}\right.$ minus $\left.\mathrm{PTA}_{\text {post }}\right) / \mathrm{PTA}_{\text {pre }}$ and relative hearing improvement compared to the contralateral ear (contral) $\Delta \mathrm{PTA}_{\text {relcontral }}=100^{*}\left(\mathrm{PTA}_{\text {pre }}\right.$ minus $\left.\mathrm{PTA}_{\text {post }}\right) /\left(\mathrm{PTA}_{\text {pre }}\right.$ minus PTA contral ). $\Delta \mathrm{PTA}_{\mathrm{abs}} \geq 10 \mathrm{~dB}, \Delta \mathrm{PTA}_{\mathrm{abs}} \geq 15 \mathrm{~dB}$, $\Delta \mathrm{PTA}_{\text {rel }} \geq 50 \%$ and $\Delta \mathrm{PTA}_{\text {relcontral }} \geq 50 \%$ in a dichotomous distribution (yes / no) were considered as criterions for a successful improvement [13]. Kanazaki et al. defines no recovery as $<10 \mathrm{~dB}$ hearing improvement relative to the initial hearing loss. Each hearing gain of $\geq 10 \mathrm{~dB}$ is defined as at least partial hearing gain, which is why an absolute hearing gain of $\geq 10 \mathrm{~dB}$ was considered as a criterion for success in the univariate analysis in this study [15]. As the endpoint of the univariate analyses, we used the 3PTAmax as it was done before $[3,14,16]$.

The epidemiological statistics were calculated on the basis of the annual average population of Thuringia from 2011 and 2012, which are published in the online database of the statistical office of the federal state of Thuringia (www.tls.thueringen.de). 
The patients affected by ISSNHL were treated according to the German guidelines for the treatment of sudden hearing loss: All patients received intravenous prednisolone therapy. Prednisolone was administered in a dose of $250 \mathrm{mg} / \mathrm{d}$ (range of $100-500 \mathrm{mg} / \mathrm{d}$ ) [7, 8]. The dose was then reduced over 7 to 10 days. If there was no improvement in hearing within 3 days under prednisolone therapy and the hearing was below $80 \mathrm{~dB}$ in 4PTA, tympanoscopy with round window membrane sealing was performed. If the hearing threshold 4PTA after 3 days of prednisolone treatment was still below $40 \mathrm{~dB}$ salvage intratympanic dexamethasone instillation was performed [7]. There was no standardized procedure for performing dexamethasone instillation. In addition to the specific treatment of the cause of their hearing loss, patients with NISSNHL received also a therapy with prednisolone according to the above-mentioned scheme. Patients with varicella zoster infection were treated with acyclovir. Patients with acute otitis media received antibiotic therapy and paracentesis. Patients with Lyme disease received doxycycline or ceftriaxone. Patients with Menière disease were treated with glucocorticoids and antivertiginous therapy.

\section{Statistical analysis}

Unless otherwise noted, data were presented with mean values \pm standard deviation (SD). All statistical analyses were performed using IBM SPSS, version 24.0.0.0. The non-parametric Mann-Whitney-U-test for independent metric data was applied to compare different subgroups of patients. The Chi-square test was applied for independent nominal data.
The non-parametric Wilcoxon test for dependent metric data was applied to analyze differences between initial hearing loss and final hearing loss on the affected ear at the end of the follow-up. A multivariate binary logistic regression was performed including the significant associations. Nominal p-values of two-tailed tests are reported. The significance level was set at $p<0.05$.

\section{Results}

\section{Subjects and treatment}

In 2011 and 2012, a total of 574 patients who were hospitalized in Thuringia for acute hearing loss were included in this study. The mean age was $57.2 \pm 16$ years. $51 \%$ of the patients were male, $49 \%$ female. 490 patients had ISSNHL (51\% male, $49 \%$ female, mean age 55.7 years \pm 15.9 years). $12 \%$ of the patients had an acute deafness and $2 \%$ had a combined vestibulocochlear lesion (Fig. 1a). In the other 84 patients, i.e. in $14.6 \%$ of cases, an underlying cause for the sudden hearing loss could be found. They were included in NISSNHL-group (54\% male, $46 \%$ female, mean age $58.7 \pm 15.8$ years). $46 \%$ had acute otitis media, $37 \%$ had an acute infection with varicella zoster or Borrelia and $10 \%$ had Menière disease (Fig. 1b). The gender distribution was the same in both groups $(p=0.218)$. There was no side predominance of acute hearing loss neither in ISSNHL nor in NISSNHL $(p=0.197)$. The accompanying symptoms like tinnitus
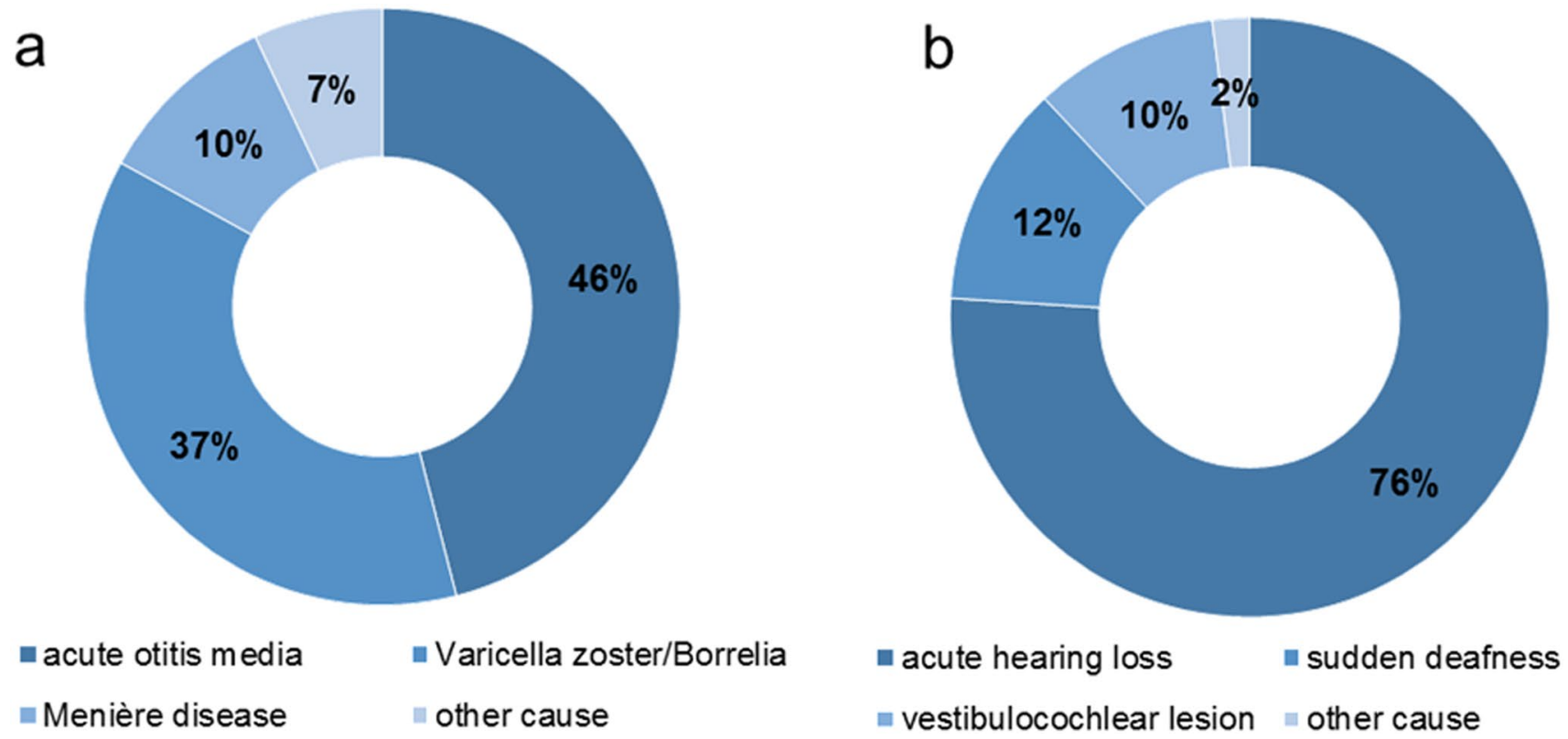

Fig. 1 Frequency of distribution of the diagnoses of a non-idiopathic sudden sensorineural hearing loss (NISSNHL) and b idiopathic sudden sensorineural hearing loss (ISSNHL) 
Table 1 Baseline characteristics and symptoms of patients with idiopathic sudden sensorineural hearing loss (ISSNHL) and patients with non-idiopathic sudden sensorineural hearing loss (NISSNHL)

\begin{tabular}{|c|c|c|c|c|c|c|c|}
\hline Patients' charac- & All patients & & NISSNHL & & ISSNHL & & \\
\hline & $N$ & $\%$ & $N$ & $\%$ & $N$ & $\%$ & $p$ \\
\hline \multicolumn{8}{|l|}{ Gender } \\
\hline Male & 294 & 51.2 & 45 & 53.6 & 251 & 50.8 & \multirow[t]{2}{*}{0.218} \\
\hline Female & 280 & 48.8 & 39 & 46.6 & 239 & 49.2 & \\
\hline \multicolumn{8}{|l|}{ Side } \\
\hline Right & 277 & 48.3 & 46 & 54.8 & 231 & 47.1 & \multirow[t]{2}{*}{0.197} \\
\hline Left & 297 & 51.7 & 38 & 45.2 & 259 & 52.9 & \\
\hline \multicolumn{8}{|l|}{ Tinnitus } \\
\hline Yes & 351 & 61.1 & 49 & 51.4 & 302 & 61.6 & \multirow[t]{3}{*}{0.743} \\
\hline No & 214 & 37.3 & 33 & 31.3 & 181 & 36.9 & \\
\hline n.a & 9 & 1.6 & 2 & 2.4 & 7 & 1.4 & \\
\hline \multicolumn{8}{|l|}{ Vertigo } \\
\hline Yes & 175 & 30.5 & 27 & 32.1 & 148 & 30.2 & \multirow[t]{4}{*}{0.605} \\
\hline No & 396 & 69 & 56 & 66.7 & 340 & 69.4 & \\
\hline \multirow[t]{2}{*}{ n.a } & 3 & 0.5 & 1 & 1.2 & 2 & 0.4 & \\
\hline & Mean & SD & Mean & SD & Mean & SD & \\
\hline Age & 57.2 & 16.0 & 55.7 & 15.9 & 58.7 & 15.8 & 0.100 \\
\hline
\end{tabular}

n.a. not available, $S D$ standard deviation
(ISSNHL: $62 \%$; NISSNHL $51 \% ; p=0.743$ ) or vertigo (ISSNHL: $30 \%$; NISSNHL 32\%; $p=0.605$ ) occurred equally frequently in both groups (Table 1). There was no significant difference in the patients' comorbidities either. Nicotine abuse $(p=0.117)$, coronary heart disease $(p=0.601)$, diabetes mellitus type II $(p=0.414)$,
Table 2 Comorbidities of patients with idiopathic sudden sensorineural hearing loss (ISSNHL) and patients with non-idiopathic sudden sensorineural hearing loss (NISSNHL)

\begin{tabular}{|c|c|c|c|c|c|c|c|}
\hline \multirow[t]{2}{*}{ Patients' characteristics } & \multicolumn{2}{|l|}{ All patients } & \multicolumn{2}{|l|}{ NISSNHL } & \multicolumn{2}{|l|}{ ISSNHL } & \multirow[b]{2}{*}{$p$} \\
\hline & $N$ & $\%$ & $N$ & $\%$ & $N$ & $\%$ & \\
\hline \multicolumn{8}{|l|}{ Smoking } \\
\hline Yes & 93 & 16.2 & 20 & 23.8 & 73 & 14.9 & 0.117 \\
\hline No & 471 & 82.1 & 63 & 75 & 408 & 83.3 & \\
\hline n.a & 10 & 1.7 & 1 & 1.2 & 9 & 1.8 & \\
\hline \multicolumn{8}{|l|}{ Coronary heart disease } \\
\hline Yes & 68 & 11.5 & 11 & 13.1 & 57 & 11.6 & 0.601 \\
\hline No & 503 & 87.6 & 72 & 85.7 & 431 & 88 & \\
\hline n.a & 3 & 0.5 & 1 & 1.2 & 2 & 0.4 & \\
\hline \multicolumn{8}{|l|}{ Diabetes } \\
\hline Yes & 92 & 16 & 16 & 19 & 76 & 15.5 & 0.414 \\
\hline No & 482 & 84 & 68 & 81 & 414 & 84.5 & \\
\hline \multicolumn{8}{|l|}{ Hypercholesterolemia } \\
\hline Yes & 76 & 13.2 & 13 & 15.5 & 63 & 12.9 & 0.755 \\
\hline No & 493 & 85.9 & 70 & 83.3 & 423 & 86.3 & \\
\hline n.a & 5 & 0.9 & 1 & 1.2 & 4 & 0.8 & \\
\hline \multicolumn{8}{|l|}{ Arterial hypertension } \\
\hline Yes & 319 & 55.6 & 48 & 57.1 & 271 & 55.3 & 0.754 \\
\hline No & 255 & 44.4 & 36 & 42.9 & 219 & 44.7 & \\
\hline \multicolumn{8}{|l|}{ Comorbidity } \\
\hline Yes & 187 & 67.2 & 30 & 35.7 & 157 & 32 & 0.742 \\
\hline No & 386 & 32.6 & 54 & 64.3 & 332 & 67.8 & \\
\hline n.a & 1 & 0.2 & 0 & 0 & 1 & 0.2 & \\
\hline
\end{tabular}

n.a. not available 
hypercholesterolemia $(p=0.755)$ and arterial hypertension $(p=0.754)$ occurred equally frequently in ISSNHL and NISSNHL (Table 2). More patients with NISSNHL (45\%) than with ISSNHL (35\%) received a prior outpatient treatment before admission to the hospital $(p<0.001)$. The time from the onset of hearing loss to hospital admission was less for NISSNHL (7.7 days \pm 12.2 days) than for ISSNHL ( 8.9 days \pm 11.8 days; $p=0.02$ ). The majority of the patients $(98.1 \%)$ received prednisolone therapy during the inpatient stay $(100 \%$ in the NISSNHL group vs. $97.8 \%$ in the ISSNHL group; $p=0.166$ ). Patients with NISSNHL had to undergo surgery during the hospital stay more often $(52 \%)$ than patients with ISSNHL $(29 \%$; $p<0.001$ ) (Table 3).

\section{Hearing loss and recovery}

The average initial hearing loss of the three most affected frequencies (3PTAmax) at NISSNHL was 67.4 $\mathrm{dBHL} \pm 30.5 \mathrm{dBHL}$ and showed no statistical difference to hearing loss at ISSNHL with a 3PTAmax of 72.9 $\mathrm{dBHL} \pm 31.3 \mathrm{~dB}(p=0.124)$. Considering the 10PTA, 9PTA, 4PTA, LF-3PTA and MF-3PTA ISSNHL had more severe hearing loss than NISSNHL $(p<0.05)$ (Table 4$)$. The pre- and post-treatment hearing level showed a significant improvement in 10PTA, 9PTA, 4PTA, LF-3PTA, MF-3PTA, HF-2PTA and 3PTAmax in NISSNHL and ISSNHL (Table 5). Under therapy, patients with NISSNHL improved by $10.2 \mathrm{~dB} \pm 17.6 \mathrm{~dB}$ and patients with ISSNHL by $8.1 \mathrm{~dB} \pm 18.8 \mathrm{~dB}$ considering the 3 PTAmax ${ }_{\text {abs }}$. There was no statistically significant difference in NISSNHL
Table 3 Therapy of patients with idiopathic sensorineural hearing loss (ISSNHL) and nonidiopathic sensorineural hearing loss (NISSNHL)
Table 4 Mean hearing loss in all patients and in patients with idiopathic (ISSNHL) and nonidiopathic sudden sensorineural hearing loss (NISSNHL)

\begin{tabular}{|c|c|c|c|c|c|c|c|}
\hline \multirow[t]{2}{*}{ Parameters } & \multicolumn{2}{|c|}{ All patients } & \multicolumn{2}{|c|}{ NISSNHL } & \multicolumn{2}{|c|}{ ISSNHL } & \multirow[t]{2}{*}{$p$} \\
\hline & $N$ & $\%$ & $N$ & $\%$ & $N$ & $\%$ & \\
\hline \multicolumn{8}{|l|}{$\begin{array}{l}\text { Outpatient } \\
\text { pretreatment }\end{array}$} \\
\hline Yes & 210 & 36.6 & 38 & 45.2 & 172 & 35.1 & $<0.001$ \\
\hline No & 362 & 63.1 & 44 & 52.4 & 318 & 64.9 & \\
\hline n.a & 2 & 0.3 & 2 & 2.4 & 0 & 0 & \\
\hline \multicolumn{8}{|l|}{ Inpatient } \\
\hline \multicolumn{8}{|l|}{ prednisolone } \\
\hline \multicolumn{8}{|l|}{ treatment } \\
\hline Yes & 563 & 98.1 & 84 & 100 & 479 & 97.8 & 0.166 \\
\hline No & 11 & 1.9 & 0 & 0 & 11 & 2.2 & \\
\hline \multicolumn{8}{|l|}{ Surgical Treatment } \\
\hline Yes & 186 & 32.4 & 44 & 52.4 & 142 & 29.0 & $<0.001$ \\
\hline No & 388 & 67.6 & 40 & 47.6 & 348 & 71 & \\
\hline \multirow{2}{*}{$\begin{array}{l}\text { Interval onset of hearing loss } \\
\text { to inpatient treatment }\end{array}$} & days & SD & days & SD & & & \\
\hline & & & 7.7 & 12.2 & 8.9 & 11.8 & 0.020 \\
\hline
\end{tabular}

n.a. not available, Significant $p$-values $(p<0.05)$ in bold, $S D$ standard deviation

\begin{tabular}{llllllll}
\hline Parameter & $\begin{array}{l}\text { all Mean } \\
\text { (dBHL) }\end{array}$ & SD (dBHL) & $\begin{array}{l}\text { ISSNHL } \\
\text { Mean } \\
(\mathrm{dBHL})\end{array}$ & SD (dBHL) & $\begin{array}{l}\text { NISSNHL } \\
\text { Mean } \\
(\mathrm{dBHL})\end{array}$ & SD (dBHL) & $p$ \\
\hline 10PTA, dBHL & 56.4 & 31.4 & 58.0 & 31.7 & 47.0 & 28.1 & $\mathbf{0 . 0 0 3}$ \\
9PTA, dBHL & 56.6 & 31.1 & 58.2 & 31.4 & 47.6 & 27.9 & $\mathbf{0 . 0 0 4}$ \\
4PTA, dBHL & 55.9 & 32.9 & 57.8 & 33.1 & 44.5 & 29.4 & $\mathbf{0 . 0 0 0}$ \\
LF-3PTA, dBHL & 50.4 & 32.8 & 52.8 & 32.8 & 36.5 & 29.6 & $\mathbf{0 . 0 0 0}$ \\
MF-3PTA, dBHL & 59.4 & 34.2 & 60.8 & 34.6 & 51.2 & 30.6 & $\mathbf{0 . 0 1 6}$ \\
HF-2PTA, dBHL & 68.0 & 37.1 & 68.3 & 37.5 & 66.1 & 34.6 & 0.616 \\
3PTAmax, dBHL & 72.1 & 31.2 & 72.9 & 31.3 & 67.4 & 30.5 & 0.124 \\
\hline
\end{tabular}

10PTA $(0.125 ; 0.25 ; 0.5 ; 1 ; 1.5 ; 2 ; 3 ; 4 ; 6 ; 8 \mathrm{kHz})$, 9PTA $(0.125 ; 0.25 ; 0.5 ; 1 ; 2 ; 3 ; 4 ; 6 ; 8 \mathrm{kHz}), 4 \mathrm{PTA}$ : $(0.5 ; 1 ; 2 ; 4 \mathrm{kHz})$, LF3PTA $(0.125 ; 0.5 ; 1 \mathrm{kHz})$ MF3PTA $(2 ; 3 ; 4 \mathrm{kHz})$, HF2PTA $(6 ; 8 \mathrm{kHz}), 3$ PTAmax (PTA of the three most affected frequencies) 


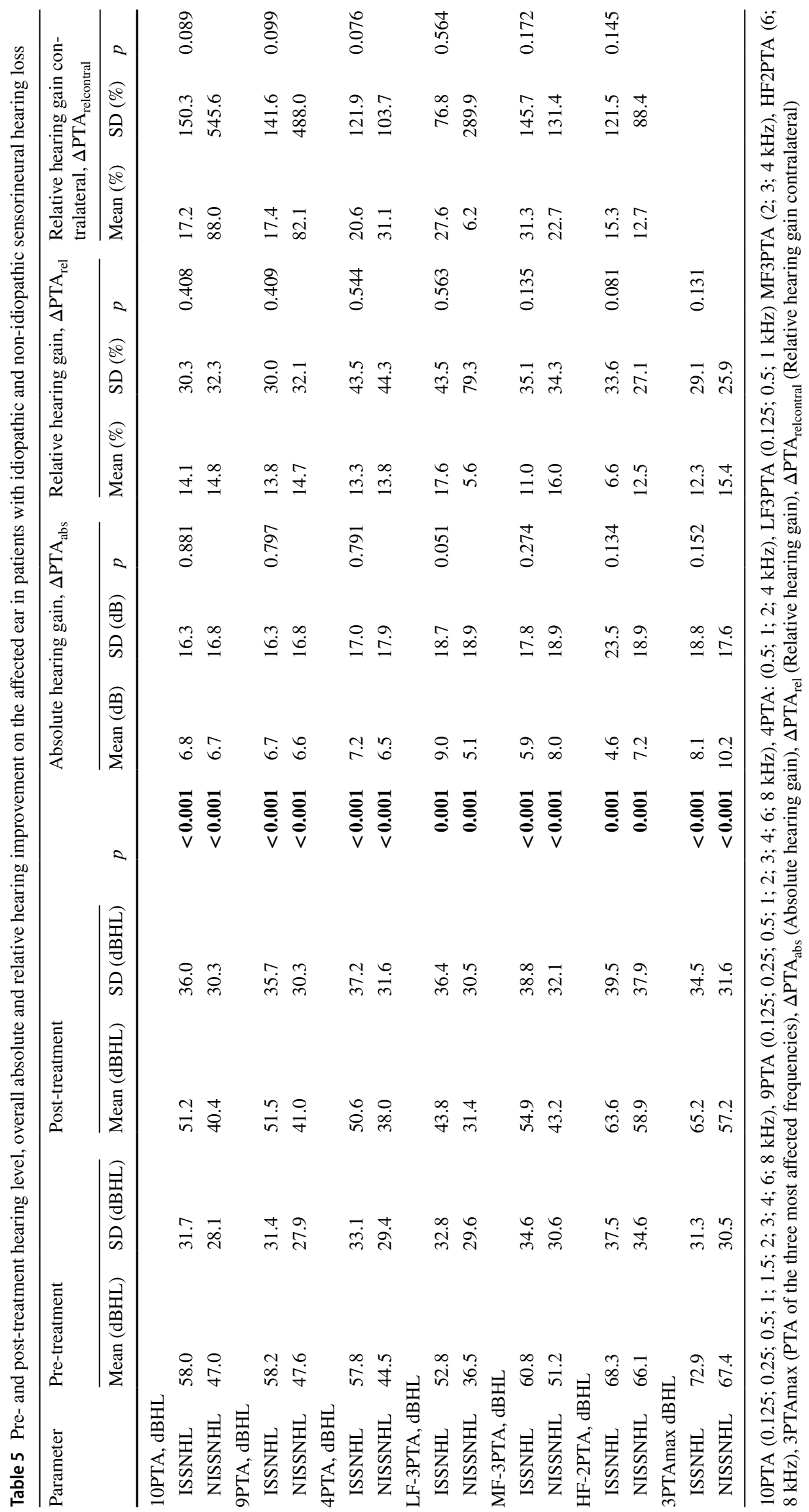


and ISSNHL considering the $\triangle \mathrm{PTA}_{\mathrm{abs}}$, the $\Delta \mathrm{PTA}_{\text {rel }}$ and the $\Delta \mathrm{PTA}_{\text {relcontral }}$ in all endpoints $(p>0.05)$ (Table 5). If $\Delta \mathrm{PTA}_{\mathrm{abs}} \geq 10 \mathrm{~dB}$ was used as the measure of successful hearing recovery, there was a significant difference in both groups: $48.8 \%$ of the NISSNHL, showed a hearing improvement of $\geq 10 \mathrm{~dB}$ in $\triangle 3$ PTAmax $_{\text {abs }}$, while for ISSNHL only $34.3 \%$ had a corresponding hearing

Table 6 Hearing recovery rates in patients with idiopathic and nonidiopathic sensorineural hearing loss

\begin{tabular}{|c|c|c|c|}
\hline Parameter & $\begin{array}{l}\text { ISSNHL } \\
(n=490)\end{array}$ & $\begin{array}{l}\text { NISSNHL } \\
(n=84)\end{array}$ & $p$ \\
\hline \multicolumn{4}{|l|}{ 10PTA, dBHL } \\
\hline$\Delta$ PTAabs $\geq 10 \mathrm{~dB}(\%)$ & 34.9 & 28.6 & 0.258 \\
\hline$\Delta$ PTAabs $\geq 15 \mathrm{~dB}(\%)$ & 24.1 & 15.5 & 0.083 \\
\hline$\Delta$ PTArel $\geq 50 \%(\%)$ & 13.9 & 9.5 & 0.277 \\
\hline$\Delta$ PTArelcontral $\geq 50 \%(\%)$ & 29.2 & 33.3 & 0.443 \\
\hline \multicolumn{4}{|l|}{ 9PTA, dBHL } \\
\hline$\Delta$ PTAabs $\geq 10 \mathrm{~dB}(\%)$ & 34.7 & 27.4 & 0.190 \\
\hline$\Delta$ PTAabs $\geq 15 \mathrm{~dB}(\%)$ & 23.1 & 16.7 & 0.192 \\
\hline$\Delta$ PTArel $\geq 50 \%(\%)$ & 13.7 & 9.5 & 0.298 \\
\hline$\Delta$ PTArelcontral $\geq 50 \%(\%)$ & 30 & 33.3 & 0.540 \\
\hline \multicolumn{4}{|l|}{ 4PTA, dBHL } \\
\hline$\Delta$ PTAabs $\geq 10 \mathrm{~dB}(\%)$ & 36.7 & 29.8 & 0.218 \\
\hline$\Delta$ PTAabs $\geq 15 \mathrm{~dB}(\%)$ & 25.5 & 19 & 0.204 \\
\hline$\Delta$ PTArel $\geq 50 \%(\%)$ & 15.7 & 9.5 & 0.140 \\
\hline$\Delta$ PTArelcontral $\geq 50 \%(\%)$ & 30.2 & 39.3 & 0.098 \\
\hline \multicolumn{4}{|l|}{ LF-3PTA, dBHL } \\
\hline$\Delta$ PTAabs $\geq 10 \mathrm{~dB}(\%)$ & 42 & 27.4 & 0.011 \\
\hline$\Delta$ PTAabs $\geq 15 \mathrm{~dB}(\%)$ & 32.2 & 17.9 & 0.008 \\
\hline$\Delta$ PTArel $\geq 50 \%(\%)$ & 21 & 17.9 & 0.508 \\
\hline$\Delta$ PTArelcontral $\geq 50 \%(\%)$ & 32.7 & 38.1 & 0.329 \\
\hline \multicolumn{4}{|l|}{ MF-3PTA, dBHL } \\
\hline$\Delta$ PTAabs $\geq 10 \mathrm{~dB}(\%)$ & 29.4 & 33.3 & 0.466 \\
\hline$\Delta$ PTAabs $\geq 15 \mathrm{~dB}(\%)$ & 22.4 & 23.8 & 0.783 \\
\hline$\Delta$ PTArel $\geq 50 \%(\%)$ & 12.9 & 14.3 & 0.720 \\
\hline$\Delta$ PTArelcontral $\geq 50 \%(\%)$ & 28.8 & 38.1 & 0.086 \\
\hline \multicolumn{4}{|l|}{ HF-2PTA, dBHL } \\
\hline$\Delta$ PTAabs $\geq 10 \mathrm{~dB}(\%)$ & 28 & 38.1 & 0.060 \\
\hline$\Delta$ PTAabs $\geq 15 \mathrm{~dB}(\%)$ & 20.4 & 21.4 & 0.831 \\
\hline$\Delta$ PTArel $\geq 50 \%(\%)$ & 10.2 & 9.5 & 0.849 \\
\hline$\Delta$ PTArelcontral $\geq 50 \%(\%)$ & 26.9 & 28.6 & 0.756 \\
\hline \multicolumn{4}{|l|}{ 3PTAmax, dBHL } \\
\hline$\Delta$ PTAabs $\geq 10 \mathrm{~dB}(\%)$ & 34.3 & 48.8 & 0.011 \\
\hline$\Delta$ PTAabs $\geq 15 \mathrm{~dB}(\%)$ & 25.9 & 28.6 & 0.610 \\
\hline$\Delta$ PTArel $\geq 50 \%(\%)$ & 10.2 & 8.3 & 0.597 \\
\hline
\end{tabular}

10PTA $(0.125 ; 0.25 ; 0.5 ; 1 ; 1.5 ; 2 ; 3 ; 4 ; 6 ; 8 \mathrm{kHz})$, 9PTA $(0.125$; $0.25 ; 0.5 ; 1 ; 2 ; 3 ; 4 ; 6 ; 8 \mathrm{kHz})$, 4PTA: $(0.5 ; 1 ; 2 ; 4 \mathrm{kHz})$, LF3PTA $(0.125 ; 0.5 ; 1 \mathrm{kHz})$ MF3PTA $(2 ; 3 ; 4 \mathrm{kHz}), \operatorname{HF} 2 \mathrm{PTA}(6 ; 8 \mathrm{kHz})$, 3PTAmax (PTA of the three most affected frequencies), $\triangle \mathrm{PTA}_{\mathrm{abs}}$ (Absolute hearing gain), $\Delta \mathrm{PTA}_{\text {rel }}$ (Relative hearing gain), $\Delta \mathrm{PTA}_{\text {relcontral }}$ (Relative hearing gain contralateral) improvement ( $p=0.011)$. In LF-3PTA $27.4 \%$ of NISSNHL and $42 \%$ of ISSNHL reached $\Delta \mathrm{PTA}_{\mathrm{abs}} \geq 10 \mathrm{~dB}(p=0.011)$ and $17.9 \%$ of NISSNHL and $32.2 \%$ of ISSNHL reached $\Delta \mathrm{PTA}_{\mathrm{abs}} \geq 15 \mathrm{~dB}$. Other parameters showed no difference in NISSNHL and ISSNHL (Table 6).

The subgroup analysis of patients with NISSNHL showed that patients with acute otitis media with 3PTAmax of $59.7 \mathrm{dBHL} \pm 24.6 \mathrm{dBHL}$ and Menière disease with 3PTAmax of $50.4 \mathrm{dBHL} \pm 12.04 \mathrm{dBHL}$ had a significantly lower initial hearing loss than the other subgroups $(p=0.033)$ (Table 7). The pre- and post-treatment hearing level showed significant differences for 3PTAmax in all subgroups. However, $\Delta \mathrm{PTA}_{\mathrm{abs}}, \Delta \mathrm{PTA}_{\text {rel }}$ and $\Delta \mathrm{PTA}_{\text {relcontral }}$ showed no differences between the subgroups (Table 8). If $\Delta$ PTArel $\geq 50 \%$ and $\Delta \mathrm{PTA}_{\text {relcontral }} \geq 50 \%$ was used as success criteria for a hearing recovery, it could be seen that the same number of patients from all subgroups met the criterion. For $\Delta \mathrm{PTA}_{\mathrm{abs}} \geq 10 \mathrm{~dB}$ and $\Delta \mathrm{PTA}_{\mathrm{abs}} \geq 15 \mathrm{~dB}$ we could show a difference in the hearing recovery rate in between the subgroups for LF-3PTA. 12,8\% of patient with acute otitis media, $45,2 \%$ of patients with varicella zoster or Borrelia, 25\% of patients with Menière disease and $16.7 \%$ others met the $\Delta \mathrm{PTA}_{\mathrm{abs}} \geq 10 \mathrm{~dB}$ for the LF3PTA $(p=0.021)$ (Table 9).

The univariate analysis of the prognostic factors showed that among the patients with NISSNHL patients without vertigo more often had a successful hearing impairment $\Delta 3$ PTAmax $_{\text {abs }} \geq 10 \mathrm{~dB}(p=0.027)$ and that more patients with prior outpatient treatment showed a hearing impairment of $\Delta$ PTAmax $_{\mathrm{abs}} \geq 10 \mathrm{~dB}(p=0.032)$. There was no difference for the tinnitus $(p=0.325)$, as well as for the comorbidities of coronary heart disease $(p=0.531)$, hypercholesterolemia $(p=0.439)$, diabetes mellitus type II $(p=0.653)$ and arterial hypertension $(p=0.850)$ (Table 10).

The multivariate analysis showed that neither vertigo nor prior outpatient treatment were independent factors associated with better hearing recovery (Table 11).

\section{Epidemiology}

Thuringia had an average of 2,176,031 (female: 1,105,434, male: 1,070,597) inhabitants in 2011 and 2012. In total, an average of 16.61 inpatients per 100,000 habitants was treated in Thuringia per year. Of these, 11.25 inpatients per 100,000 habitants had an ISSNHL and 1.93 per 100,000 inhabitant people per year had an NISSNHL $(0.89 / 100,000$ for acute otitis media, $0.71 / 100,000$ for varicella zoster or Borrelia and 0.18/100,000 for Menière disease). There was no difference in gender distribution. The incidence of the ISSNHL was 21.6/100,000 in women and 23.4/100,000 in men. The incidence of NISSNHL was 3.5/100,000 in women and 4.2/100,000 in men. 
Table 7 Mean hearing loss in subgroups of non-idiopathic sudden sensorineural hearing loss (NISSNHL)

\begin{tabular}{|c|c|c|c|c|c|c|c|c|c|}
\hline Parameter & $\begin{array}{l}\text { AOM } \\
\text { Mean } \\
(\mathrm{dBHL})\end{array}$ & $\mathrm{SD}(\mathrm{dBHL})$ & $\begin{array}{l}\text { VZB Mean } \\
\text { (dBHL) }\end{array}$ & $\mathrm{SD}(\mathrm{dBHL})$ & $\begin{array}{l}\text { M Mean } \\
\text { (dBHL) }\end{array}$ & $\mathrm{SD}(\mathrm{dBHL})$ & O Mean (dBHL) & $\mathrm{SD}(\mathrm{dBHL})$ & $\mathrm{p}$ \\
\hline 10PTA, dBHL & 36.9 & 16.5 & 62.5 & 34.7 & 32.7 & 9.3 & 52.3 & 32.0 & 0.007 \\
\hline 9PTA, dBHL & 37.7 & 16.8 & 62.7 & 34.4 & 33.8 & 9.4 & 52.8 & 32.0 & 0.010 \\
\hline 4PTA, dBHL & 32.8 & 14.5 & 62.4 & 36.6 & 27.5 & 9.5 & 50.6 & 31.2 & 0.001 \\
\hline LF-3PTA, dB HL & 21.5 & 13.9 & 55.8 & 35.7 & 33.5 & 7.9 & 38.9 & 35.5 & 0.000 \\
\hline MF-3PTA, dBHL & 43.1 & 17.9 & 66.3 & 37.8 & 25.4 & 15.0 & 60.6 & 32.8 & 0.002 \\
\hline HF-2PTA, dBHL & 62.3 & 29.8 & 75.6 & 38.7 & 41.3 & 18.8 & 75.4 & 43.1 & 0.062 \\
\hline 3PTAmax dBHL & 59.7 & 24.6 & 80.1 & 34.2 & 50.4 & 12.0 & 74.7 & 40.2 & 0.033 \\
\hline
\end{tabular}

AOM Acute otitis media, $V Z B$ Varicella zoster/Borrelia, $M$ Menière disease, $O$ Other cause, $10 \mathrm{PTA}(0.125 ; 0.25 ; 0.5 ; 1 ; 1.5 ; 2 ; 3 ; 4 ; 6 ; 8 \mathrm{kHz})$, 9PTA $(0.125 ; 0.25 ; 0.5 ; 1 ; 2 ; 3 ; 4 ; 6 ; 8 \mathrm{kHz}), 4 \mathrm{PTA}:(0.5 ; 1 ; 2 ; 4 \mathrm{kHz})$, LF3PTA $(0.125 ; 0.5 ; 1 \mathrm{kHz})$ MF3PTA $(2 ; 3 ; 4 \mathrm{kHz})$, HF2PTA (6; 8 kHz), 3PTAmax (PTA of the three most affected frequencies)

\section{Discussion}

\section{Key findings}

In the current study, causes for sensorineural hearing losses were found in $14.6 \%$, which corresponds to the numbers reported so far [7]. There were no differences between patients with ISSNHL and NISSNHL in terms of risk factors and accompanying symptoms. The extent of the initial absolute hearing loss tended to be higher in patients with ISSNHL compared to NISSNHL but the absolute and relative hearing recovery showed no difference. If according to Plontke et al. an absolute improvement of the pure tone average by $\geq 10 \mathrm{~dB}$ is used as a criterion for a successful hearing recovery, it can be seen that patients with NISSNHL show a successful hearing recovery more often than patients with ISSNHL considering the $\Delta 3$ PTAmax $_{\text {abs }}[13]$. An explanatory model offers the possibility of using specific therapy options in the case of NISSNHL (acyclovir, antibiotics) [17, 18], while at ISSNHL therapy decisions are made without knowledge of the etiology of the hearing loss [7].

\section{Strength and limitations}

Studies that directly compare ISSNHL and NISSNHL are not known. Therefore, the retrospective study presented here with a total of 490 patients with ISSNHL and 84 patients with NISSNHL is the largest study of this type published to date. One disadvantage of the current study is that only patients with acute hearing loss were included here. Patients treated in hospital with the ICD codes H65.0, H65.1, H65.2, H65.3 H65.4 H65.9, H66.0, H66.1, H66.2, H66.3, H66.4, H66.9, H67.0* H67.1*, H67.8*, H83.0, H73.0, J11.8,H70.0, H70.2, H70 0.8, H70.9, B02.8 and A69.2 for any underlying disease were not included. Therefore, there is an unreported number of patients with other diseases combined with sensorineural hearing loss. Likewise, the true incidence of diseases is underestimated here because only patients who have been hospitalized are included in this evaluation. This is associated with a selection bias in favor of the more severe cases. The evaluation of hearing loss and hearing gain is handled inconsistently in most studies [19-21]. So far, there is no consensus on the evaluation of hearing loss and hearing recovery in the pure tone audiogram [13]. The different criteria for evaluating the hearing loss and hearing gain make it difficult to compare studies with one another. In addition, the evaluation of different endpoints in this analysis also shows different results.

\section{Comparison with other studies}

The data on the occurrence, extent and recovery of ISSNHL have already been discussed in detail elsewhere [3]. Therefore, we now focus on the data of NISSNHL. The incidence of acute otitis media is $10.85 \%$ [22]. The incidence of zoster oticus is $5 / 100,000$ inhabitants [23]. The incidence of Lyme disease is 0.04 / 100,000 inhabitants, which is strongly dependent on the region [24]. Menière disease has an incidence of $200 / 100,000$ inhabitants [25]. The epidemiological data diverge greatly in the evaluation published here. The reason might be that, as mentioned before, ICD-codes for underlying illnesses of hearing loss are not included here.

In addition to potentially life-threatening complications, acute otitis media can lead to a permanent impairment of the patient due to hearing loss [22]. A zoster oticus can lead to accompanying facial palsy or vestibular failure in the context of Ramsay Hunt syndrome [20, 26]. Overall, the detection of Borrelia titers is controversial in the diagnosis of acute hearing loss. Numerous studies have shown a connection between Borrelia detection and sudden hearing loss, while others see no connection [27-32]. In Menière disease, hearing loss is one of the diagnostic criteria of the Bárány Society and the AAO-HNS guideline [33, 34]. It is noticeable that hearing impairment has different values in 


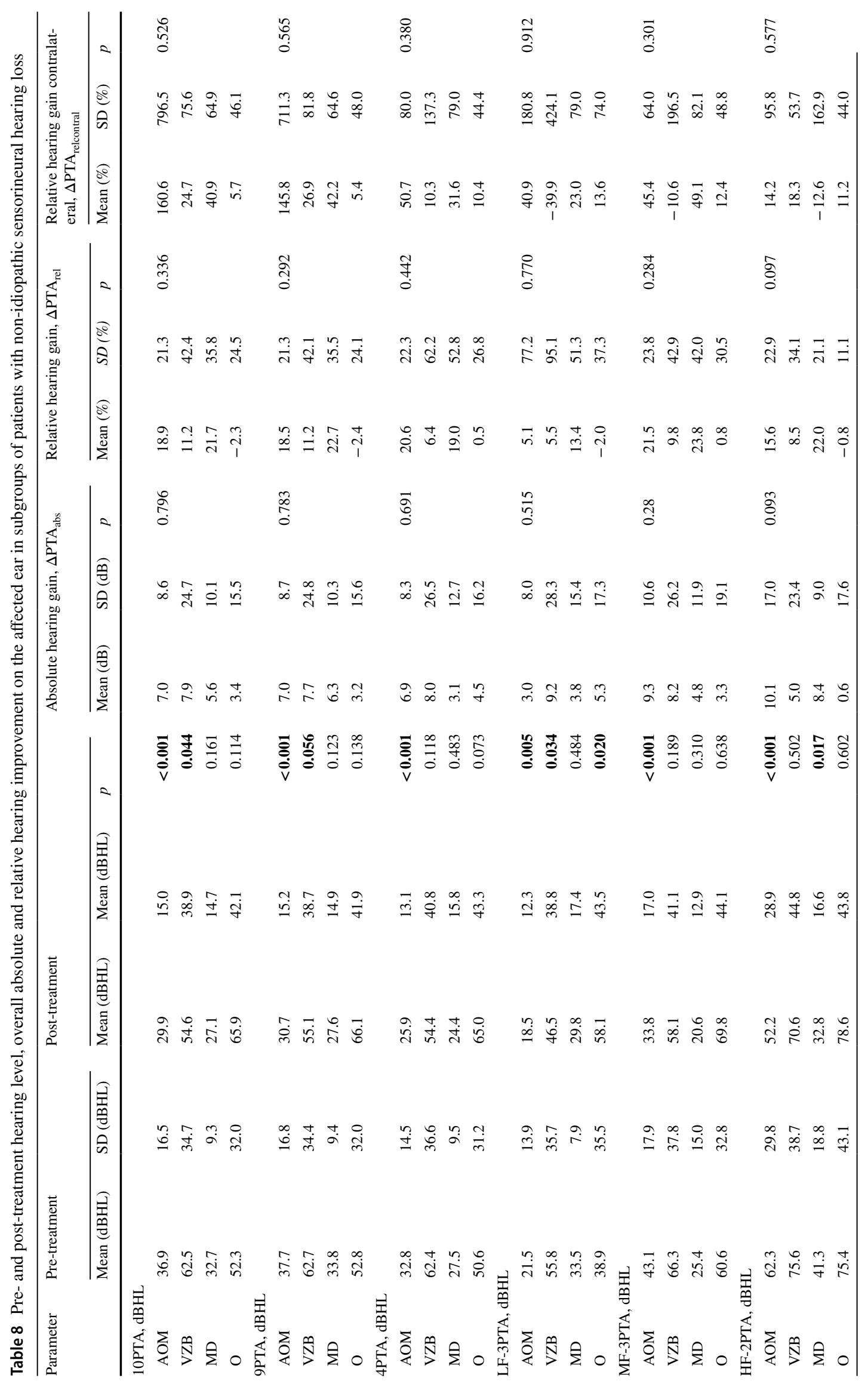




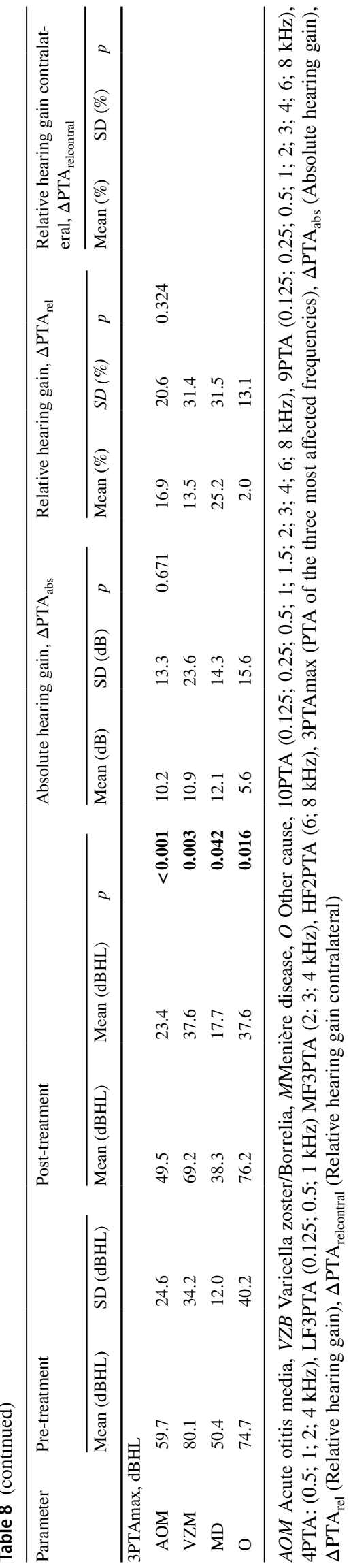

Table 9 Hearing recovery rates in subgroups of pathients with nonidiopathic sensorineural hearing loss

\begin{tabular}{|c|c|c|c|c|c|}
\hline Parameter & $\mathrm{AOM}$ & VZB & M & $\mathrm{O}$ & $\mathrm{p}$ \\
\hline \multicolumn{6}{|l|}{ 10PTA, dBHL } \\
\hline$\Delta$ PTAabs $\geq 10 \mathrm{~dB}(\%)$ & 23.1 & 35.5 & 37.5 & 16.7 & 0.571 \\
\hline$\Delta$ PTAabs $\geq 15 \mathrm{~dB}(\%)$ & 10.3 & 19.4 & 25 & 16.7 & 0.635 \\
\hline$\Delta$ PTArel $\geq 50 \%(\%)$ & 7.7 & 9.7 & 25 & 0 & 0.396 \\
\hline$\Delta$ PTArelcontral $\geq 50 \%(\%)$ & 33.3 & 35.5 & 37.5 & 16.7 & 0.833 \\
\hline \multicolumn{6}{|l|}{ 9PTA, dBHL } \\
\hline$\Delta$ PTAabs $\geq 10 \mathrm{~dB}(\%)$ & 23.1 & 32.3 & 25 & 16.7 & 0.688 \\
\hline$\Delta$ PTAabs $\geq 15 \mathrm{~dB}(\%)$ & 12.8 & 19.4 & 25 & 16.7 & 0.810 \\
\hline$\Delta$ PTArel $\geq 50 \%(\%)$ & 7.7 & 9.7 & 25 & 0 & 0.395 \\
\hline$\Delta$ PTArelcontral $\geq 50 \%(\%)$ & 35.9 & 32.3 & 37.5 & 16.7 & 0.818 \\
\hline \multicolumn{6}{|l|}{ 4PTA, dBHL } \\
\hline$\Delta$ PTAabs $\geq 10 \mathrm{~dB}(\%)$ & 28.2 & 35.5 & 37.5 & 16.7 & 0.778 \\
\hline$\Delta$ PTAabs $\geq 15 \mathrm{~dB}(\%)$ & 15.4 & 22.6 & 25 & 16.7 & 0.853 \\
\hline$\Delta$ PTArel $\geq 50 \%(\%)$ & 7.7 & 9.7 & 25 & 0 & 0.396 \\
\hline$\Delta$ PTArelcontral $\geq 50 \%(\%)$ & 46.2 & 32.3 & 50 & 16.7 & 0.384 \\
\hline \multicolumn{6}{|l|}{ LF-3PTA, dBHL } \\
\hline$\Delta$ PTAabs $\geq 10 \mathrm{~dB}(\%)$ & 12.8 & 45.2 & 25 & 16.7 & 0.021 \\
\hline$\Delta$ PTAabs $\geq 15 \mathrm{~dB}(\%)$ & 5.1 & 32.3 & 37.5 & 0 & 0.008 \\
\hline$\Delta$ PTArel $\geq 50 \%(\%)$ & 15.4 & 22.6 & 25 & 0 & 0.534 \\
\hline$\Delta$ PTArelcontral $\geq 50 \%(\%)$ & 38.5 & 41.9 & 25 & 33.3 & 0.843 \\
\hline \multicolumn{6}{|l|}{ MF-3PTA, dBHL } \\
\hline$\Delta$ PTAabs $\geq 10 \mathrm{~dB}(\%)$ & 35.9 & 35.5 & 25 & 16.7 & 0.761 \\
\hline$\Delta$ PTAabs $\geq 15 \mathrm{~dB}(\%)$ & 25.6 & 25.8 & 12.5 & 16.7 & 0.834 \\
\hline$\Delta$ PTArel $\geq 50 \%(\%)$ & 17.9 & 6.5 & 37.5 & 0 & 0.093 \\
\hline$\Delta$ PTArelcontral $\geq 50 \%(\%)$ & 41 & 35.5 & 25 & 33.3 & 0.962 \\
\hline \multicolumn{6}{|l|}{ HF-2PTA, dBHL } \\
\hline$\Delta$ PTAabs $\geq 10 \mathrm{~dB}(\%)$ & 41 & 35.5 & 50 & 16.7 & 0.602 \\
\hline$\Delta$ PTAabs $\geq 15 \mathrm{~dB}(\%)$ & 28.2 & 19.4 & 12.5 & 16.7 & 0.816 \\
\hline$\Delta$ PTArel $\geq 50 \%(\%)$ & 5.1 & 12.9 & 25 & 0 & 0.252 \\
\hline$\Delta$ PTArelcontral $\geq 50 \%(\%)$ & 30.8 & 25.8 & 37.5 & 16.7 & 0.819 \\
\hline \multicolumn{6}{|l|}{ 3PTAmax, dBHL } \\
\hline$\Delta$ PTAabs $\geq 10 \mathrm{~dB}(\%)$ & 51.3 & 48.4 & 50 & 33.3 & 0.880 \\
\hline$\Delta$ PTAabs $\geq 15 \mathrm{~dB}(\%)$ & 7.7 & 25.8 & 50 & 16.7 & 0.511 \\
\hline$\Delta$ PTArel $\geq 50 \%(\%)$ & 5.1 & 9.7 & 25 & 0 & 0.261 \\
\hline
\end{tabular}

AOM: Acute otitis media, VZB: Varicella zoster/Borrelia, M:Menière disease, O: Other cause, 10PTA $(0.125 ; 0.25 ; 0.5 ; 1 ; 1.5 ; 2 ; 3 ; 4 ; 6$; $8 \mathrm{kHz})$, 9PTA $(0.125 ; 0.25 ; 0.5 ; 1 ; 2 ; 3 ; 4 ; 6 ; 8 \mathrm{kHz}), 4 \mathrm{PTA}:(0.5$; $1 ; 2 ; 4 \mathrm{kHz})$, LF3PTA $(0.125 ; 0.5 ; 1 \mathrm{kHz})$ MF3PTA $(2 ; 3 ; 4 \mathrm{kHz})$, HF2PTA $(6 ; 8 \mathrm{kHz}), 3$ PTAmax (PTA of the three most affected frequencies), $\Delta \mathrm{PTA}_{\mathrm{abs}}$ (Absolute hearing gain), $\Delta \mathrm{PTA}_{\text {rel }}$ (Relative hearing gain), $\Delta \mathrm{PTA}_{\text {relcontral }}$ (Relative hearing gain contralateral)

the underlying diseases. While in acute otitis media there is a complicated course in the case of sensorineural hearing loss, the detection of at least one episode of sensorineural hearing loss is a prerequisite for the diagnosis of Menière disease.

In the present study, it was found that acute otitis media and Menière disease showed significantly less absolute hearing loss compared to the other subgroups. Many evaluations 
Table 10 Univariate association between patients' and treatment characteristics versus a successful recovery defined as $\Delta$ PPTAmax $_{\mathrm{abs}} \geq 10 \mathrm{~dB}(N=84)$

\begin{tabular}{|c|c|c|c|}
\hline Parameter & $\Delta 3 \mathrm{PTAmax}_{\mathrm{abs}}<10 \mathrm{~dB}$ & $\Delta 3 \mathrm{PTAmax}_{\mathrm{abs}} \geq 10 \mathrm{~dB}$ & $p$ \\
\hline \multicolumn{4}{|l|}{ Patients'characteristics } \\
\hline Gender & & & 0.083 \\
\hline Male & 27 & 18 & \\
\hline Female & 16 & 23 & \\
\hline Side & & & 0.524 \\
\hline Right & 25 & 21 & \\
\hline Left & 18 & 20 & \\
\hline Tinnitus & & & 0.325 \\
\hline Yes & 25 & 24 & \\
\hline No & 16 & 17 & \\
\hline n.a & 2 & 0 & \\
\hline Vertigo & & & $\mathbf{0 . 0 2 7}$ \\
\hline Yes & 19 & 8 & \\
\hline No & 23 & 33 & \\
\hline n.a & 1 & 0 & \\
\hline Smoking & & & 0.557 \\
\hline Yes & 11 & 9 & \\
\hline No & 32 & 31 & \\
\hline n.a & 0 & 1 & \\
\hline Coronary heart disease & & & 0.531 \\
\hline Yes & 5 & 6 & \\
\hline No & 38 & 34 & \\
\hline n.a & 0 & 1 & \\
\hline Diabetes mellitus type II & & & 0.653 \\
\hline Yes & 9 & 7 & \\
\hline No & 34 & 34 & \\
\hline Hypercholesterolemia & & & 0.439 \\
\hline Yes & 8 & 5 & \\
\hline No & 35 & 35 & \\
\hline n.a & 0 & 1 & \\
\hline Arterial hypertension & & & 0.850 \\
\hline Yes & 25 & 23 & \\
\hline No & 18 & 18 & \\
\hline Comorbidity & & & 0.454 \\
\hline Yes & 17 & 13 & \\
\hline No & 26 & 23 & \\
\hline Prior outpatient treatment & & & $\mathbf{0 . 0 3 2}$ \\
\hline Yes & 14 & 24 & \\
\hline No & 27 & 17 & \\
\hline n.a & 2 & 0 & \\
\hline Surgical treatment & & & 0.835 \\
\hline Yes & 23 & 21 & \\
\hline No & 20 & 20 & \\
\hline
\end{tabular}

3PTAmax (PTA of the three most affected frequencies), $\triangle \mathrm{PTA}_{\mathrm{abs}}$ (Absolute hearing gain) consider hearing loss, but often no distinction is made between the appearance of conductive hearing loss and sensorineural hearing loss. Occasionally the absolute extent of hearing loss (in dBHL) is not described. For acute otitis media hearing loss is reported between 25 and $40 \mathrm{dBHL}$ [19, 22, 35-37]. Hearing loss in zoster oticus is reported in 7-85\% of patients with an extend of 10dBHL to 20dBHL [20, 21, 38-40], while hearing loss in case of Borrelia infection is considered in approximately $12 \%$ [41]. The largest clinical trial examining Menière disease includes 350 patients. This showed fluctuating curves 
Table 11 Multivariate binary regression of predictors of successful improvement of hearing $\Delta 3$ PTAmax $_{\mathrm{abs}} \geq 10 \mathrm{~dB}$

\begin{tabular}{lrlcl}
\hline Parameter & \multicolumn{1}{l}{ B } & 95\% CI lower & 95\% CI upper & $p$ \\
\hline Vertigo & 0.009 & -0.096 & 0.114 & 0.865 \\
$\begin{array}{l}\text { Prior outpa- } \\
\text { tient treat- }\end{array}$ & -0.001 & 0.397 & -0.002 & 0.397 \\
ment & & & & \\
\hline
\end{tabular}

CI confidence interval

in the pure tone audiogram at the beginning of the disease and an average hearing threshold of 26 to $40 \mathrm{dBHL}$ [42]. In summary, one subgroup in this study showed a higher absolute hearing loss in the used endpoints (Varicella / Borrelia: range 55.8dBHL - 80.1dBHL), whereas initial PTA of the others (acute otitis media: range $21.5 \mathrm{dBHL}-59.7 \mathrm{dBHL}$, Menière disease range: $25.4-50.42 \mathrm{dBHL}$ ) considering the different endpoints is the same as reported in the underlying literature. Explanations might be the already mentioned bias to more severe cases and difficulties in comparison of different studies reporting a hearing loss.

So far, there is no guideline for the treatment of acute otitis media with sensorineural hearing loss in Germany. The German Society for General Medicine and Family Medicine published a S2k-guideline "Earache": In the guideline, initially symptomatic treatment and, in the event of a lack of improvement or indications of a complicated course, antibiotics are used [43]. In acute otitis media, the patients in the studies considered were treated with oral antibiotics [19, 36]. Oral corticosteroids and paracentesis with or without tympanic drainage were optionally performed [19]. Patients with herpes zoster oticus were treated intravenously with acyclovir [44]. There is a German S2k-guideline in which anti-viral therapy in combination with glucocorticoid therapy is recommended for zoster oticus, but this guideline does not give specific recommendations regarding a related sensorineural hearing loss [45]. Patients with Lyme disease are treated with ceftriaxone or doxycycline depending on the stage of the disease [41]. The treatment strategies in the current study thus corresponded to current treatment recommendations. In $87.5 \%$ of cases with acute otitis media and sensorineural hearing loss there was an improvement in hearing of at least $10 \mathrm{~dB}$ on average with $5 \mathrm{PTA}(500 \mathrm{~Hz}$, $1 \mathrm{kHz}, 2 \mathrm{kHz}, 3 \mathrm{kHz}, 4 \mathrm{kHz}$ ) [19]. In the current evaluation, there was no difference in hearing improvement after therapy in between all subgroups.

\section{Conclusion}

The current retrospective study examines inpatients with ISSNHL and NISSNHL in Thuringia in 2011 and 2012. It can be seen that ISSNHL tends to have a higher initial hearing loss than patients with NISSNHL. ISSNHL and NISSNHL show no difference in the degree of absolute or relative hearing improvement. However, patients with NISSNHL are more likely to show successful hearing improvement considering the 3PTAmax. The data are not sufficient to show prognostic differences of subgroups at NISSNHL. However, we were able to show that patients with acute otitis media and Menière disease show an initially lower hearing loss compared to patients with varicella zoster or Lyme disease or other underlying diseases.

Supplementary Information The online version contains supplementary material available at https://doi.org/10.1007/s00405-021-06691-y.

Author contributions OGL developed the idea for the study. JT made the first draft of the manuscript. All authors contributed patients' data to the study. AH administered the database. AH and OGL revised the final database. JT performed the statistical analyses. All authors analyzed and interpreted the data. All authors revised the manuscript. JT is the guarantor.

Funding Open Access funding enabled and organized by Projekt DEAL. The authors received no specific funding for this work.

Data availability All authors had full access to all of the data in the study. JT takes responsibility for the integrity of the data and the accuracy of the data analysis. No additional data are available.

\section{Compliance with ethical standards}

Conflict of interests The authors have declared that no competing interests exist.

Open Access This article is licensed under a Creative Commons Attribution 4.0 International License, which permits use, sharing, adaptation, distribution and reproduction in any medium or format, as long as you give appropriate credit to the original author(s) and the source, provide a link to the Creative Commons licence, and indicate if changes were made. The images or other third party material in this article are included in the article's Creative Commons licence, unless indicated otherwise in a credit line to the material. If material is not included in the article's Creative Commons licence and your intended use is not permitted by statutory regulation or exceeds the permitted use, you will need to obtain permission directly from the copyright holder. To view a copy of this licence, visit http://creativecommons.org/licenses/by/4.0/.

\section{References}

1. Wu CS et al (2013) Sudden sensorineural hearing loss associated with chronic periodontitis: a population-based study. Otol Neurotol 34(8):1380-1384

2. Alexander TH, Harris JP (2013) Incidence of sudden sensorineural hearing loss. Otol Neurotol 34(9):1586-1589

3. Heuschkel A et al (2018) Inpatient treatment of patients with idiopathic sudden sensorineural hearing loss: a populationbased healthcare research study. Eur Arch Otorhinolaryngol 275(3):699-707

4. Edizer DT et al (2015) Recovery of Idiopathic Sudden Sensorineural Hearing Loss. J Int Adv Otol 11(2):122-126 
5. Conlin AE, Parnes LS (2007) Treatment of sudden sensorineural hearing loss: II A Meta-analysis. Arch Otolaryngol Head Neck Surg 133(6):582-586

6. Mattox DE, Simmons FB (1977) Natural history of sudden sensorineural hearing loss. Ann Otol Rhinol Laryngol 86(4 Pt 1):463-480

7. Stachler RJ et al (2012) Clinical practice guideline: sudden hearing loss. Otolaryngol Head Neck Surg 146(3 Suppl):S1-35

8. Michel O, Ku H-C (2011) Deutsche Gesellschaft fur Hals-NasenOhren-Heilkunde, The revised version of the german guidelines "sudden idiopathic sensorineural hearing loss. Laryngorhinootologie 90(5):290

9. Haynes DS et al (2007) Intratympanic dexamethasone for sudden sensorineural hearing loss after failure of systemic therapy. The Laryngoscope 117(1):3-15

10. Klemm E, Deutscher A, Mösges R (2009) A present investigation of the epidemiology in idiopathic sudden sensorineural hearing loss. Laryngo- rhino- otologie 88(8):524-527

11. Renner V et al (2017) Inpatient Treatment of Patients Admitted for Dizziness: A Population-Based Healthcare Research Study on Epidemiology, Diagnosis, Treatment, and Outcome. Otol Neurotol 38(10): $460-\mathrm{e} 469$

12. Fiedler T et al (2013) Middle ear surgery in Thuringia, Germany: a population-based regional study on epidemiology and outcome. Otol Neurotol 34(5):890-897

13. Plontke SK, Bauer M, Meisner C (2007) Comparison of puretone audiometry analysis in sudden hearing loss studies: lack of agreement for different outcome measures. Otol Neurotol 28(6):753-763

14. Suckfuell M et al (2014) Efficacy and safety of AM-111 in the treatment of acute sensorineural hearing loss: a double-blind, randomized, placebo-controlled phase II study. Otol Neurotol 35(8):1317-1326

15. Kanzaki J et al (2003) Effect of single-drug treatment on idiopathic sudden sensorineural hearing loss. Auris Nasus Larynx 30(2):123-127

16. Nosrati-Zarenoe R, Hultcrantz E (2012) Corticosteroid treatment of idiopathic sudden sensorineural hearing loss: randomized triple-blind placebo-controlled trial. Otol Neurotol 33(4):523-531

17. Chau JK et al (2010) Systematic review of the evidence for the etiology of adult sudden sensorineural hearing loss. Laryngoscope 120(5):1011-1021

18. Merchant SN, Adams JC, Nadol JB Jr (2005) Pathology and pathophysiology of idiopathic sudden sensorineural hearing loss. Otol Neurotol 26(2):151-160

19. Park JH et al (2014) Sensorineural hearing loss: a complication of acute otitis media in adults. Eur Arch Otorhinolaryngol 271(7):1879-1884

20. Kim CH, Choi H, Shin JE (2016) Characteristics of hearing loss in patients with herpes zoster oticus. Medicine (Baltimore) 95(46): e5438

21. Kaberos A et al (2002) Audiological assessment in Ramsay Hunt syndrome. Ann Otol Rhinol Laryngol 111(1):68-76

22. Monasta $\mathrm{L}$ et al (2012) Burden of disease caused by otitis media: systematic review and global estimates. PLoS ONE 7(4):e36226

23. Murakami S et al (1997) Treatment of Ramsay Hunt syndrome with acyclovir-prednisone: significance of early diagnosis and treatment. Ann Neurol 41(3):353-357

24. Rizzoli A et al (2011) Lyme borreliosis in Europe. Euro Surveill $16: 27$

25. Plontke SK, Gurkov R (2015) Meniere's Disease. Laryngorhinootologie 94(8):530-554
26. Walther LE et al (2004) Herpes zoster oticus: symptom constellation and serological diagnosis. Laryngorhinootologie 83(6):355-362

27. Hanner P (1995) Borreliosis may cause hearing defects in children. Screening of Borrelia infection. Lakartidningen 92(3):174-175

28. Hanner $P$ et al (1989) Hearing impairment in patients with antibody production against Borrelia burgdorferi antigen. Lancet 1(8628):13-15

29. Moscatello AL et al (1991) Otolaryngologic aspects of Lyme disease. Laryngoscope 101(6 Pt 1):592-595

30. Riechelmann $\mathrm{H}$ et al (1990) The Borrelia titer in ENT diseases. Laryngorhinootologie 69(2):65-69

31. Bakker R et al (2012) No evidence for the diagnostic value of Borrelia serology in patients with sudden hearing loss. Otolaryngol Head Neck Surg 146(4):539-543

32. Saunders JE (2013) Routine testing for Borrelia serology in sudden sensorineural hearing loss. Otolaryngol Head Neck Surg 148(1):179-180

33. Lopez-Escamez JA et al (2015) Diagnostic criteria for Meniere's disease. J Vestib Res 25(1):1-7

34. Lopez-Escamez JA et al (2016) Diagnostic criteria for Meniere's disease. Consensus document of the Barany Society, the Japan Society for Equilibrium Research, the European Academy of Otology and Neurotology (EAONO), the American Academy of Otolaryngology-Head and Neck Surgery (AAO-HNS) and the Korean Balance Society. Acta Otorrinolaringol Esp 67(1):1-7

35. Kasemodel, A.L.P., et al., Sensorineural hearing loss in the acute phase of a single episode of acute otitis media. Braz J Otorhinolaryngol, 2019.

36. Cordeiro FP et al (2018) Extended high-frequency hearing loss following the first episode of otitis media. Laryngoscope 128(12):2879-2884

37. Paparella MM et al (1984) Sensorineural hearing loss in otitis media. Ann Otol Rhinol Laryngol 93(6 Pt 1):623-629

38. Kim J et al (2008) Statistical analysis of pure tone audiometry and caloric test in herpes zoster oticus. Clin Exp Otorhinolaryngol 1(1):15-19

39. Byl FM, Adour KK (1977) Auditory symptoms associated with herpes zoster or idiopathic facial paralysis. Laryngoscope 87(3):372-379

40. Wayman DM et al (1990) Audiological manifestations of Ramsay Hunt syndrome. J Laryngol Otol 104(2):104-108

41. Peltomaa M et al (2000) Lyme borreliosis, an etiological factor in sensorineural hearing loss? Eur Arch Otorhinolaryngol 257(6):317-322

42. Savastano M, Guerrieri V, Marioni G (2006) Evolution of audiometric pattern in Meniere's disease: long-term survey of 380 cases evaluated according to the 1995 guidelines of the American Academy of Otolaryngology-Head and Neck Surgery. J Otolaryngol 35(1):26-29

43. Mühlenfeld H-M, Saal K (2005) Die neue DEGAM-Leitlinie Nr. 7 „Ohrenschmerzen”. ZFA-Zeitschrift für Allgemeinmedizin 81(12):544-549

44. Wagner G, Klinge H, Sachse MM (2012) Ramsay Hunt syndrome. J Dtsch Dermatol Ges 10(4):238-244

45. Gross GE et al (2020) S2k-Leitlinie zur Diagnostik und Therapie des Zoster und der Postzosterneuralgie. Journal der Deutschen Dermatologischen Gesellschaft 18(1):55-79

Publisher's Note Springer Nature remains neutral with regard to jurisdictional claims in published maps and institutional affiliations. 